Bull. Mater. Sci., Vol. 39, No. 6, October 2016, pp. 1609-1618. (c) Indian Academy of Sciences.

\title{
Morphology, thermal stability and thermal degradation kinetics of cellulose-modified urea-formaldehyde resin
}

\author{
M A ARSHAD ${ }^{1}$, A MAAROUFI ${ }^{1, *}$, G PINTO $^{2}$, S EL-BARKANY $^{3}$ and A ELIDRISSI ${ }^{3}$ \\ ${ }^{1}$ University of Mohammed V, Faculty of Sciences, Department of Chemistry, Laboratory of Composite Materials, \\ Polymers and Environment, Avenue Ibn Batouta, P.O. Box 1014, Rabat-Agdal 10106, Morocco \\ ${ }^{2}$ Departamento de Ingeniería Química Industrial y del Medio Ambiente, E.T.S.I. Industriales, \\ Universidad Politécnica de Madrid, Madrid 28006, Spain \\ ${ }^{3}$ Laboratory of Applied Chemistry and Environment, Faculty of Sciences, Med I University, Oujda 60000, Morocco
}

MS received 10 November 2015; accepted 15 April 2016

\begin{abstract}
This article reports a study on the structural characterization and evaluation of thermal degradation kinetics of urea-formaldehyde resin modified with cellulose, known as UFC resin. Structural characterization of UFC undertaken by scanning electron microscopy, Fourier transform infrared and X-ray diffraction analyses reveals that the resin is fairly homogenous, and it constitutes of partly crystalline structure including ureaformaldehyde/cellulose interface morphology different from UFC precursors. Measurement of inherent thermal stability, probing reaction complexity and the thermal degradation kinetic analysis of UFC have been carried out by thermogravimetric/differential thermal analyses (TGA/DTA) under non-isothermal conditions. The integral procedure decomposition temperature elucidates significant thermal stability of UFC. TGA/DTA analyses suggest highly complicated reaction profile for thermal degradation of UFC, comprising various parallel/consecutive reactions. Different differential and integral isoconversional methods have been employed to determine the thermal degradation activation energy of UFC. Substantial variation in activation energy with the advancement of reaction verifies multi-step reaction pathway of UFC. A plausible interpretation of the obtained kinetic parameters of UFC thermal degradation with regard to their physical meanings is given and discussed in this study.
\end{abstract}

Keywords. UFC resin; structure; TGA/DTA; thermal degradation kinetics; activation energy.

\section{Introduction}

Urea-formaldehyde resin belongs to the class of synthetic thermosetting resins. It is formed by permanent interlinking of urea and formaldehyde in aqueous state by following condensation reaction. The obtained colourless, syrupy solution is mixed with cellulose filler to produce powders for moulding into solid objects, known as urea-formaldehyde cellulose or simply UFC [1,2]. UFC thus formed is an environment friendly and cheap resin with good thermal, electrical and chemical resistance, dimensional stability and excellent adhesion. It therefore finds numerous industrial applications including decorative laminates, textiles, paper, foundry and moulds, wrinkle-resistant fabrics, cotton blends, wood gluing and electrical appliance casings [3-7]. It is capable of serving as a polymer matrix in UFC/metal composites, which shows interesting electrical/dielectric properties with a number of worldwide applications [8-11].

Kinetic analysis of thermally activated condensed phase processes is capable of determining their activation parameters, i.e., activation energies and pre-exponential factors in order to analyse their transition states, and eventually their

\footnotetext{
*Author for correspondence (maaroufi@fsr.ac.ma, akarimmaaroufi@gmail.com)
}

process mechanisms. Kinetic parameters are practically useful in predicting thermal stability/life of materials outside the experimental conditions. One must, however, take into consideration the fact that the complexity of thermal degradation reactions is well known and even an outwardly simple reaction might constitute several reactions with variable energies of activation and multi-step reaction pathways [1215]. Isoconversional kinetic analysis provides an appropriate way to probe these processes. This type of kinetic analysis deals with the variation in mechanism as a result of variation in activation energy with the advancement of reaction. Accordingly, isoconversional kinetic analysis is particularly valuable in the case of processes obeying complicated reaction pathways [12-15]. For that reason, this approach has been frequently and effectively employed in various emerging research domains including fuel processing and technology [16], valorization of waste and biomass [17-19], high energy materials [20] and organic photovoltaics [21]. The reliability/reproducibility of isoconversional methods regarding to the evaluation of reaction mechanisms and kinetic predictions has already been elaborated [12].

This research work focuses on the structural characterization and evaluation of thermal degradation kinetics of UFC resin by employing isoconversional kinetic analysis. The light will also be shed on the complex reaction profile of UFC 
resulting from the combination of individual thermal degradation pathways of urea-formaldehyde and cellulose, and their mutual interactions. Some invaluable structural parameters will be calculated to obtain the insights into UFC morphology, and an account of kinetic predictions on the basis of isoconversional kinetic analysis will be given and discussed.

\section{Kinetic analysis of thermally stimulated solid-state processes}

The extent of solid-state processes is effectively described by a term degree of conversion ' $\alpha$ ' and is defined as following:

$$
\alpha=\frac{m_{0}-m_{t}}{m_{0}-m_{\infty}}
$$

where $m_{0}$ is the initial mass of reactant, ' $m_{t}$ ' its mass at certain time during the reaction and ' $m_{\infty}$ ' its mass at the end of reaction. In these processes, the reaction rate $\mathrm{d} \alpha / \mathrm{d} t$ being the function of ' $\alpha$ ' can be represented as

$$
\frac{\mathrm{d} \alpha}{\mathrm{d} t}=k f(\alpha) .
$$

Equation (2) is the basic kinetic equation of solid-state mass loss processes. In the case of thermally stimulated solid-state processes, the value of rate constant ' $k$ ' is often substituted in equation (2) by Arrhenius equation, which then takes the following form:

$$
\frac{\mathrm{d} \alpha}{\mathrm{d} t}=A \exp \left(-E_{\alpha} / \mathrm{RT}\right) f(\alpha) .
$$

In equation (3), $A$ is pre-exponential factor, $E_{\alpha}$ the energy of activation and $f(\alpha)$ a function of degree of conversion, called reaction model. Physically, $A$ describes the collision frequency of particles involved in the formation of activated complex, $E_{\alpha}$ the activation energy barrier of reaction and $f(\alpha)$ furnishes information about the mechanism of reaction(s) [22].

\subsection{Estimation of activation energy by isoconversional kinetic analysis}

Isoconversional methods are employed to examine the variation in activation energy with degree of conversion and to estimate the effective values of activation energies for the processes. They are categorized in the following sections.

\section{1a Differential isoconversional methods:}

2.1a1 Freidman's linear differential method: Taking logarithm of equation (3) and rearranging it, gives the following differential isoconversional method, known as Friedman's method [23].

$$
\ln (\mathrm{d} \alpha / \mathrm{d} t)_{\alpha, \beta}=-E_{\alpha} / \mathrm{RT}_{\alpha, \beta}+\ln A f(\alpha) .
$$

The $E_{\alpha}$ values can be determined by plotting $\ln (\mathrm{d} \alpha / \mathrm{d} t)$ against $1 / T$ at certain values of $\alpha$, which preliminarily requires numerical differentiation of thermoanalytical data. The resulting $E_{\alpha}$ values might therefore be significantly irregular. A data-smoothening filter is recommended in this case in order to reduce the noise in data.

2.1a2 Non-linear differential method: In recent approaches to the mechanisms of solid-state processes, it has been pointed out that the pre-exponential factor and activation energy do not remain constant during the course of the solidstate processes; instead, they are the functions of degree of conversion and temperature [24]. The pre-exponential factor varies with temperature by following the given relationship:

$$
A=A_{0}\left(\frac{T}{T_{0}}\right)^{n}
$$

where $A_{0}$ is the value of pre-exponential factor at initial temperature $T_{0}$ and $n$ a numerical constant. It is a known fact that the influence of temperature on pre-exponential factor is less significant in comparison with the temperature dependence of $\exp \left(-E_{\alpha} / \mathrm{RT}\right)$ term in equation (3) to simulate the reaction rates [25]. However, kinetic equations including temperature-dependent pre-exponential factors are supposed to determine the activation energies in a relatively more precise way. Putting the value of $A$ from equation (5) into equation (3) generates the following equation.

$$
\frac{\mathrm{d} \alpha}{\mathrm{d} t}=A_{0}\left(T / T_{0}\right)^{n} \exp \left(-E_{\alpha} / \mathrm{RT}\right) f(\alpha)
$$

Equation (6) obtained by slightly modifying equation (3) might be highly useful in the kinetic modelling of solid-state processes as

- The errors in the activation energy values can be significantly larger if the dependence of the pre-exponential factor on the temperature is neglected [26].

- The parameter ' $n$ ' in equation (6) is helpful in extracting rather detailed mechanistic information complementary to $f(\alpha)$ as shown in table 1 .

- The advanced reaction model determination methodology [24] demands the determination of parameter ' $n$ ' in order to evaluate relatively more accurate values of reaction models especially when $E_{\alpha} / \mathrm{RT}$ attains lower values, as described in equations (7) and (8):

$$
\frac{f^{\prime}(\alpha)}{f(\alpha)}=\frac{\mathrm{d} E / \mathrm{d} \alpha}{\mathrm{RT}}-\frac{\beta}{T(\mathrm{~d} \alpha / \mathrm{d} t)}\left\{n+\frac{E_{\alpha}}{\mathrm{RT}}\right\}+\frac{\mathrm{d}^{2} \alpha / \mathrm{d} t^{2}}{(\mathrm{~d} \alpha / \mathrm{d} t)^{2}},
$$

$$
\frac{f^{\prime}(\alpha)}{f(\alpha)}=\frac{1}{(\mathrm{~d} \alpha / \mathrm{d} t)}\left[\frac{\beta(\mathrm{d} E / \mathrm{d} T)}{\mathrm{RT}}-\frac{\beta}{T}\left\{n+\frac{E_{\alpha}}{\mathrm{RT}}\right\}+\frac{\mathrm{d}^{2} \alpha / \mathrm{d} t^{2}}{\mathrm{~d} \alpha / \mathrm{d} t}\right]
$$

Under invariant conditions of $\alpha$, equation (6) can be transformed into the following equation:

$$
y=a(x)^{b} \exp (-c / x)
$$


Table 1. Different values of parameter $n$ in equation (6) with their probable physical meanings [27-30].

\begin{tabular}{ll}
\hline Parameter, $n$ & \multicolumn{1}{c}{ Physical significance } \\
\hline 1 & Thermal decomposition of a single reactive solid \\
$1 / 2$ & Reaction between gas and surface of a solid \\
$0-5 / 2$ & Desorption of gases from solid surfaces \\
$-3 / 2$ to 0 & Shrinkage processes depending on sintering mechanism \\
\hline
\end{tabular}

where $x=T, y=\mathrm{d} \alpha / \mathrm{d} t ; a=\varphi(\alpha)=\left\{A_{0} /\left(T_{0}\right)^{n}\right\} f(\alpha)$, $b=n, c=E_{\alpha} / R$.

Equation (9) provides basis for non-linear differential isoconversional method. As the reaction rate varies exponentially with temperature, the variation in reaction rate with temperature at constant values of $\alpha$ can be fitted by a userdefined fitting function, based on equation (9), employing Levenberg-Marquardt algorithm (LMA) for 2D curves [31] which results in the generation of parameters $a, b$ and $c$.

2.1b Linear integral isoconversional methods: Numerical differentiation can be avoided by using integral methods. In this way, integration of equation (3) results in the following:

$$
\begin{aligned}
g(\alpha) & =\int_{0}^{\alpha} \mathrm{d} \alpha / f(\alpha)=A / \beta \int_{0}^{T} \exp (-E / \mathrm{RT}) \mathrm{d} T \\
& =(A / \beta) I(E, T),
\end{aligned}
$$

where $g(\alpha)$ is called the integrated reaction model in equation (10). Equation (10) contains temperature integral $I(E, T)$, which has no analytical solution [32]. A number of approximations was applied to numerically solve the temperature integral yield, see the following generalized expression [15]:

$$
\ln \left(\frac{\beta}{T_{\alpha}^{b}}\right)=\text { Const. }-\left(\frac{a E_{\alpha}}{\mathrm{RT}_{\alpha}}\right)
$$

In equation (11), $a$ and $b$ are constants that arise from different approximations of temperature integral. For instance, $(a, b)=(1.052,0)$ for Ozawa-Flynn-Wall (OFW) method [33], $(a, b)=(1,2)$ in the case of Kissinger-Akahira-Sunose (KAS) method [34] and $(a, b)=(1.0008,1.92)$ in the case of Starink's method [35], etc.

2.1b1 Generalized linear integral isoconversional method: A generalized linear integral isoconversional method has been recently put forward by mathematically treating equation (11), which results in equation (12) [24]:

$$
E_{\alpha}=-\frac{R}{a}\left[\frac{\mathrm{d} \ln \beta}{\mathrm{d}\left(1 / T_{\alpha}\right)}-b \frac{\mathrm{d} \ln T_{\alpha}}{\mathrm{d}\left(1 / T_{\alpha}\right)}\right],
$$

where $\mathrm{d} \ln \beta / \mathrm{d}\left(1 / T_{\alpha}\right)$ and $\mathrm{d} \ln T_{\alpha} / \mathrm{d}\left(1 / T_{\alpha}\right)$ are the slopes of straight lines drawn between $\ln \beta$ and $1 / T_{\alpha}$, and $\ln T_{\alpha}$ and $1 / T_{\alpha}$ at each value of $\alpha$, respectively. The activation energy of any linear integral isoconversional method at any value of $\alpha$ can be directly determined by employing equation (12), provided that the values of the constants $a$ and $b$ are known and the values of $\mathrm{d} \ln \beta / \mathrm{d}\left(1 / T_{\alpha}\right)$ and $\mathrm{d} \ln T_{\alpha} / \mathrm{d}\left(1 / T_{\alpha}\right)$ at the relevant values of $\alpha$ are known.

2.1c Non-linear integral method: An advanced isoconversional method: A numerically accurate non-linear integral method, called advanced isoconversional method, has been suggested by solving equation (10) using numerical integration within the infinitesimally small intervals of extent of conversion [36]. The general expression for the advanced isoconversional method is given in equation (13):

$$
\Phi\left(E_{\alpha}\right)=\sum_{i=1}^{n} \sum_{j^{1} i}^{n} \frac{J\left[E_{\alpha}, T_{i}\left(t_{\alpha}\right)\right]}{J\left[E_{\alpha}, T_{j}\left(t_{\alpha}\right)\right]},
$$

where $J\left[E_{\alpha}, T\left(t_{\alpha}\right)\right]$ is the notation in equation (13) for integration with respect to time over an infinitesimally small interval $[\alpha, \alpha+\Delta \alpha]_{\Delta \alpha \rightarrow 0}$, and is defined as following:

$$
J\left[E_{\alpha}, T\left(t_{\alpha}\right)\right]=\int_{\alpha}^{\alpha+\Delta \alpha} \exp \left(-E_{\alpha} / \mathrm{RT}(t)\right) \mathrm{d} t,
$$

According to this method, the activation energy at each value of $\alpha$ is the value that minimizes $\Phi\left(E_{\alpha}\right)$ function.

\section{Experimental}

\subsection{Materials}

Commercial grade urea-formaldehyde resin filled with $\alpha$ cellulose, having $1.38 \mathrm{~g} \mathrm{~cm}^{-3}$ density, was supplied by Aicar S.A (Cerdanyola del Vallès, Spain). The total contents of $\alpha$-cellulose contained by UFC resin were $30 \%$ by weight.

\subsection{Structural characterization by SEM, FTIR and XRD analyses}

The internal morphology of UFC, the phase distribution of $\alpha$-cellulose and urea-formaldehyde in UFC and the homogeneity of UFC were analysed by cross-sectional scanning electron microscopy (SEM). The scanning electron microscope SEM-Philips XL30 with an accelerating voltage up to $20 \mathrm{kV}$ was employed for the said purpose.

Fourier transform infrared (FTIR) analysis of UFC resin was carried out by employing attenuated total reflection technique in a Vertex 70 spectrometer equipped with a 
Digitec detector. The resin was scanned in transmission mode with $4 \mathrm{~cm}^{-1}$ resolution in the wavenumber range of $4000-400 \mathrm{~cm}^{-1}$.

X-ray diffraction (XRD) analysis was carried out by $X$ 'pert Pro diffractometer for determining the number and types of internal phases present inside UFC. Fairly thick disk-shaped sample of UFC was introduced into diffractometer containing copper anode $(\lambda=1.54 \AA$ ) within the Bragg's angle $2 \theta \epsilon\left(3^{\circ}, 90^{\circ}\right)$.

\subsection{Thermogravimetric/differential thermal analyses}

In order to carry out the thermogravimetric/differential thermal analyses (TGA/DTA) measurements, different UFC samples of nearly similar geometries with masses ranging from 10 to $15 \mathrm{mg}$ were used. The analyses were performed by SHIMADZU TA-60WS thermal analyzer containing an aluminium pan, employing non-isothermal experiment mode with $\beta=5,10,15,20^{\circ} \mathrm{C} \mathrm{min}^{-1}$ from 25 to $500^{\circ} \mathrm{C}$ under $50 \mathrm{~cm}^{3} \mathrm{~min}^{-1}$ of nitrogen flow.

\section{Results and discussion}

\subsection{Structural characterization by SEM}

The results obtained by performing cross-sectional SEM analysis under the conditions described in Experimental section have been shown in figure 1 . Figure $1 \mathrm{a}$ and $\mathrm{b}$ represent, respectively, the morphologies of UFC by magnifying 500 and 1000 times the original image size. Different phases present in a SEM micrograph are identified by their differences in colours, contrasts and the geometries of particles. The SEM micrograph in figure 1 broadly depicts two different phases in UFC due to their colour contrast; although the distribution of these phases is fairly homogeneous throughout the resin. These results reveal the homogeneity of UFC resin, and suggest that the resin can be subjected to further structural analysis and thermoanalytical studies.
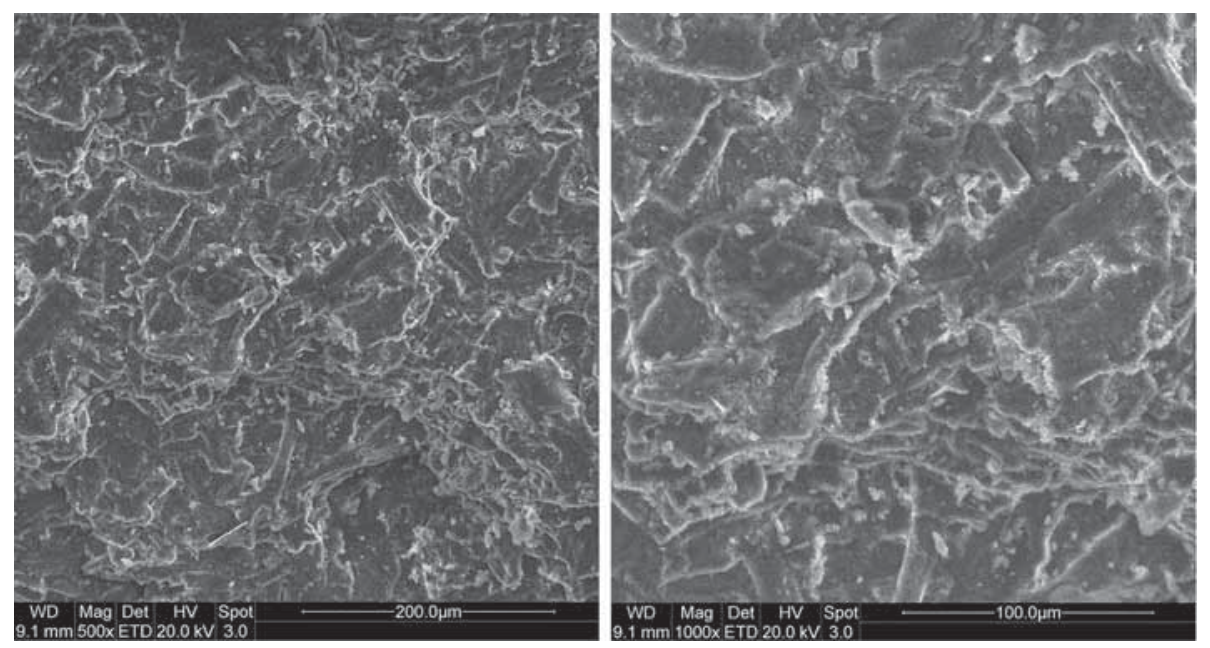

\subsection{FTIR analysis}

The individual molecular structures of cellulose and ureaformaldehyde as well as the FTIR-ATR spectrum of UFC resin are shown in figure 2. Apparently, the infrared spectrum of UFC seems highly complicated due to the structural complexities of its precursors. The FTIR spectra of the individual components of UFC are therefore helpful in explaining its morphology. A significantly broadband around 3650$3000 \mathrm{~cm}^{-1}$ is a convoluted band as both urea-formaldehyde and cellulose absorb in this region. It comprises a peak around $3350-3450 \mathrm{~cm}^{-1}$ that can be attributed to the hydrogen bonded $\mathrm{O}-\mathrm{H}$ and $\mathrm{N}-\mathrm{H}$, and its broadness might be due to the monomers such as water and formaldehyde. The $\mathrm{O}-\mathrm{H}$ groups of water and formaldehyde of UFC may form hydrogen bonds with reactive functional groups such as $\mathrm{CH}_{2} \mathrm{OH}$, $\mathrm{NH}_{2}$ and $\mathrm{NH}$ [37]. This convoluted band also includes a peak at $3337 \mathrm{~cm}^{-1}$ corresponding to $\mathrm{OH}$ stretching, related to the intramolecular hydrogen bonds of cellulose [38]. However, there is a difference in the broadness and the position of the peak at the area of $3350 \mathrm{~cm}^{-1}$, which is shifted to the lower wavenumbers due to the interactions between ureaformaldehyde and cellulose and probably resulting in the formation of hydrogen bonds between them. The two small bands in the region of 2920 and $2850 \mathrm{~cm}^{-1}$ are typical of the $\mathrm{C}-\mathrm{H}$ and $\mathrm{O}-\mathrm{H}$ stretching vibrations of cellulose/hemicellulose and lignin, respectively [39].

The overlapped peaks at the area $1500-1600 \mathrm{~cm}^{-1}$ are attributed to $-\mathrm{N}-\mathrm{H}$ bending vibrations of amide II ( $\mathrm{sec}$ ondary). Relatively small peaks at the area of 1320$1450 \mathrm{~cm}^{-1}$ can be assigned to the stretching $\mathrm{C}-\mathrm{N}$ vibrations of amide I and II (primary and secondary), while it has also been assigned to $\mathrm{C}-\mathrm{H}$ stretching and $-\mathrm{O}-\mathrm{H}$ bending vibrations of alcohol [40]. The intense and broad peak at $1230 \mathrm{~cm}^{-1}$ is assigned to $\mathrm{C}-\mathrm{N}$ stretching vibrations of amide II [41]. The peak at $1159 \mathrm{~cm}^{-1}$ is attributed to both the asymmetric stretches of $\mathrm{N}-\mathrm{CH}_{2}-\mathrm{N}$ and $-\mathrm{C}-\mathrm{O}-\mathrm{C}-$ of ether linkages [42]. The strong peak at $1017 \mathrm{~cm}^{-1}$ is due to $\mathrm{C}-\mathrm{C}-\mathrm{O}$

Figure 1. Scanning electron micrographs of UFC resin. 
<smiles>CCN(C)C(C=O)NCCN(C)C</smiles>

Urea formaldehyde

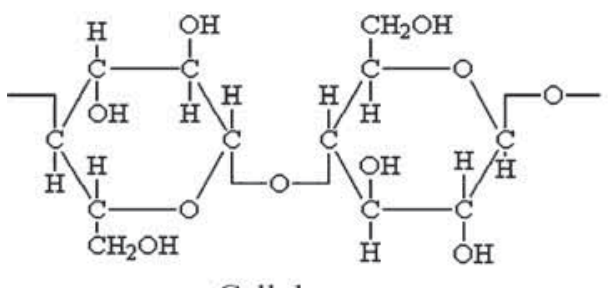

Cellulose

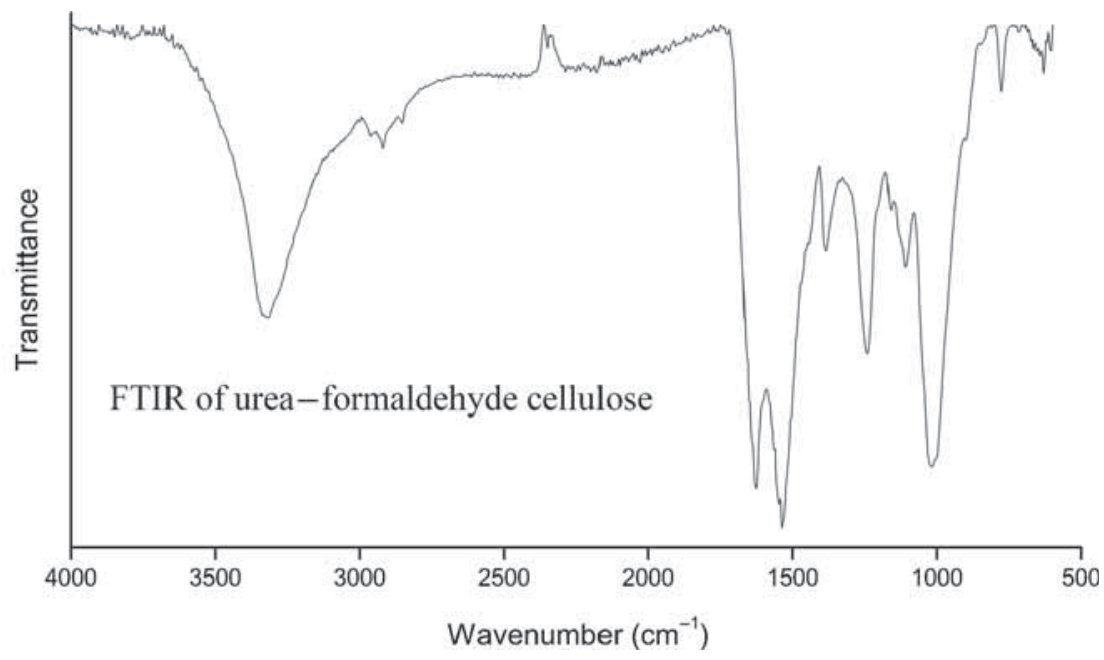

Figure 2. Individual molecular structures of urea-formaldehyde and cellulose, and FTIR spectrum of UFC resin.

stretching mode of $\mathrm{CH}_{2} \mathrm{OH}$ and the small peak at $770 \mathrm{~cm}^{-1}$ is due to $-\mathrm{N}-\mathrm{H}$ bending and wagging vibrations of amide I and II [40].

\subsection{XRD analysis of UFC}

The results obtained by performing the XRD of UFC, under the conditions discussed in the Experimental section, are presented in figure 3 with $2 \theta \in\left(10^{\circ}, 60^{\circ}\right)$. The diffractogram in figure 3 shows clearly that the internal structure of UFC is highly complicated due to the structural complexities of individual components and the interactions between them. Nine different peaks are observed in figure 3 and labelled as numbers. Peaks $1-2$ existing at $14.17^{\circ}$ and $15.35^{\circ}$ are the overlapped geminal peaks, which are the characteristics of crystalline phases present in the cellulose [43]. Partially overlapped peaks $3-4$ available at $20.56^{\circ}$ and $21.96^{\circ}$ can be attributed, respectively, to the crystalline phase present in urea-formaldehyde $[44,45]$, and the amorphicity of cellulose [43]. Peaks 5-6 existing near $26^{\circ}$ and $30^{\circ}$ are also typical peaks of urea-formaldehyde $[44,45]$. It is worth noticing that the two characteristic peaks of cellulose and ureaformaldehyde around $35^{\circ}$ and $41^{\circ}$, respectively $[43,45]$, are absent and instead, three new sharp peaks $7-9$ at $47.34^{\circ}$, $51.54^{\circ}$ and $56.19^{\circ}$ with relatively lower intensities appear. Similar peaks were observed in the case of interpenetrating urea-formaldehyde $/ \mathrm{SiO}_{2}$ composites [45]. These peaks have been attributed to the presence of new crystalline morphologies due to the interactions between urea-formaldehyde and $\mathrm{SiO}_{2}$, which result in the formation of hydrogen bonds between urea-formaldehyde and silanol groups of $\mathrm{SiO}_{2}$ [44]. It can be said that the interactions between ureaformaldehyde and cellulose in UFC resin might be analogous to those present in urea-formaldehyde/ $/ \mathrm{SiO}_{2}$, giving rise to the existence of certain new phases in UFC.

4.3a Evaluation of CI of UFC: An interesting and important parameter extracted from XRD analysis is the

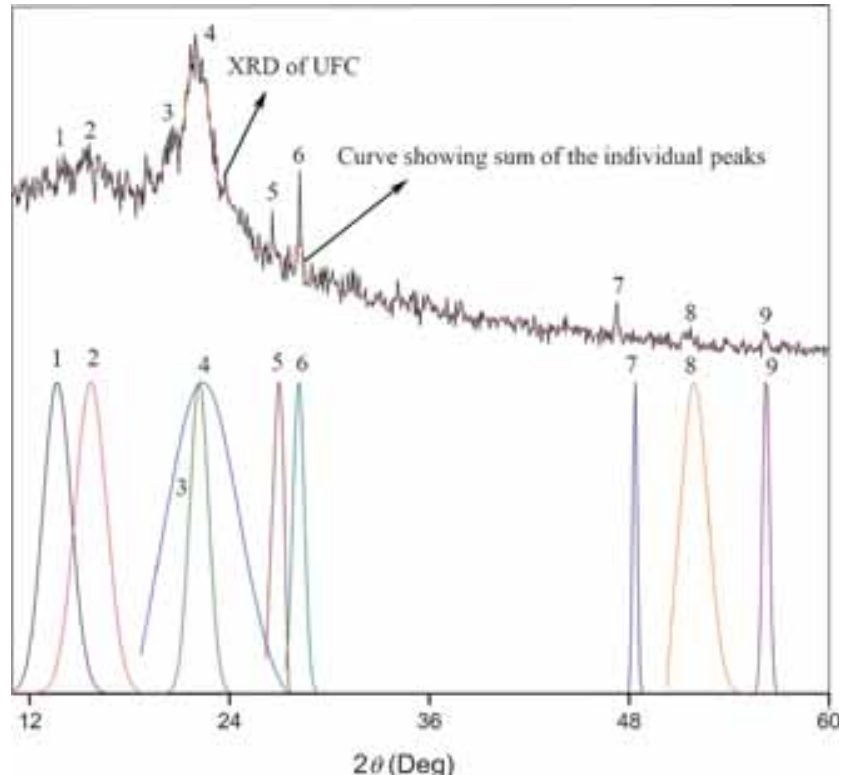

Figure 3. X-ray diffractograms of UFC and representation of the $\mathrm{XRD}$ peak deconvolution procedure to determine the crystallinity index (CI).

crystallinity index denoted by CI and describes the percentage crystallinity of amorphous materials. Several methods are available to calculate CI; yet, XRD peak deconvolution is considered comparatively more efficacious [43]. A representation of this method has been given in figure 2 by the individual deconvoluted peaks and peak sum. The CI is calculated by the following formula:

$\mathrm{CI}=\frac{\text { Total crystalline area in X-ray diffractogram }}{\text { Total area of X-ray diffractogram }} \times 100$.

The CI calculated by the method discussed above and by employing equation (15) has been found to be 23.13 for UFC. 
It shows that roughly one-fourth of the total UFC consists of crystalline phases.

\subsection{Thermal degradation of UFC}

The percentage mass loss values, DTA data and normalized thermal degradation rates of UFC, at different heating rates as functions of temperature, generated by SHIMADZU TA-60WS thermal analyzer under the experimental conditions described in Experimental section are represented in figure $4 \mathrm{a}$ and $\mathrm{b}$.

The complexity of degradation process is determined by the shape and position of TGA/DTA curve and it strongly depends on the components contained by the material. Therefore, in order to understand the thermal degradation behaviour of UFC, it is necessary to recall the individual thermal degradation behaviours of both the ureaformaldehyde and cellulose. Urea-formaldehyde is known to degrade in four successive but sparingly overlapping steps. The first two steps range between 50 and $200^{\circ} \mathrm{C}$, which are attributed to the dehydration of polymer, weak linkages like hydrogen bonding and particularly to the transformation of methyl ether bridges into methylene bridges following branching and crosslinking reactions [42,44,46]. The third step takes place above $200-300^{\circ} \mathrm{C}$, in which the radicals formed by chain scission participate in the formation of polymeric cyclic structures [47]. The fourth step above $400^{\circ} \mathrm{C}$ is attributed to extensive fragmentation or char formation [48]. On the other hand, thermal degradation of cellulose follows three steps [49,50]. The first step is assigned to the cellulose dehydration, ranges usually between 50 and $150^{\circ} \mathrm{C}$. The second step at $250-420^{\circ} \mathrm{C}$ is in fact a combination of two steps; i.e., the formation of active cellulose that is associated with the scission of glycosidic bonds and the dehydration of pyranose rings, producing hydrocellulose, $\mathrm{CO}_{2}$, volatile gases and unsaturated cyclic compounds [51]. The last degradation step above $420^{\circ} \mathrm{C}$ is related to the formation of char, which normally occurs in all the polymeric materials.

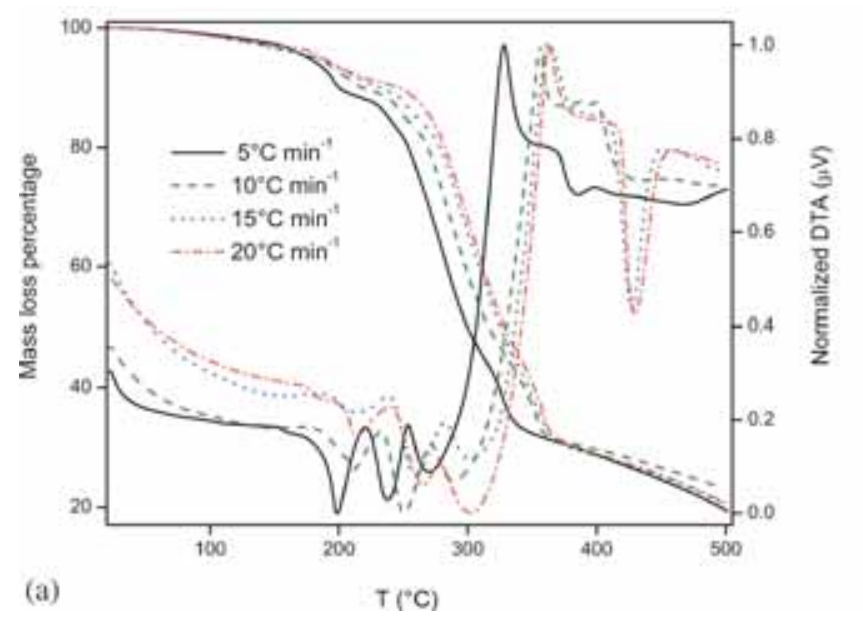

The individual thermal degradation behaviours of ureaformaldehyde and cellulose suggest that the thermal degradation behaviour of UFC could be highly complicated. It is evident in figure $4 \mathrm{a}$ and $\mathrm{b}$ that the reaction profile of UFC consists of a number of complex processes. The thermal degradation behaviour of UFC resin, as represented by figure $4 \mathrm{a}$ and $\mathrm{b}$, could possibly be explained on the basis of individual thermal degradation behaviours of UFC precursors and its structural characterization results. TGA/DTA curves in figure $4 \mathrm{a}$ show that the thermal degradation of UFC resin goes to completion by following not less than four steps. The first step ranges between 50 and $230^{\circ} \mathrm{C}$, which may comprise the dehydration of resin, the scission of weaker intermolecular/intramolecular linkages like hydrogen bonding, polymer-polymer interactions, etc. The total mass loss of resin is $11 \%$ at this stage. The second step ranges between 230 and $270^{\circ} \mathrm{C}$ with a total mass loss of $22 \%$. The dominant reaction here could be the conversion of methyl ether functional groups into methylene functional groups [46], which would probably be shifted to somewhat higher temperatures due to the presence of interactions between urea-formaldehyde and cellulose. The existence of interactions between urea-formaldehyde and cellulose has already been evidenced by FTIR and XRD results of UFC. The third step can be found between 270 and $350^{\circ} \mathrm{C}$ with more than $50 \%$ mass loss. In this step, at least two competitive reactions might take place due to the possibility of their occurrence in the similar temperature ranges. More predominantly, these reactions constitute of the principle degradation reactions of urea-formaldehyde and cellulose [47,51]. At this stage, the reaction rates of these parallel reactions may convolute to generate a twist in reaction rate peak as can be seen in figure $3 \mathrm{~b}$. The final step is the formation of residue, which takes place above $350^{\circ} \mathrm{C}$ and noticeable in DTA/reaction rate peaks.

4.4a Inherent thermal stability of UFC: Thermal stability of materials can be investigated using TGA by a number of ways including, initial decomposition temperature (IDT),

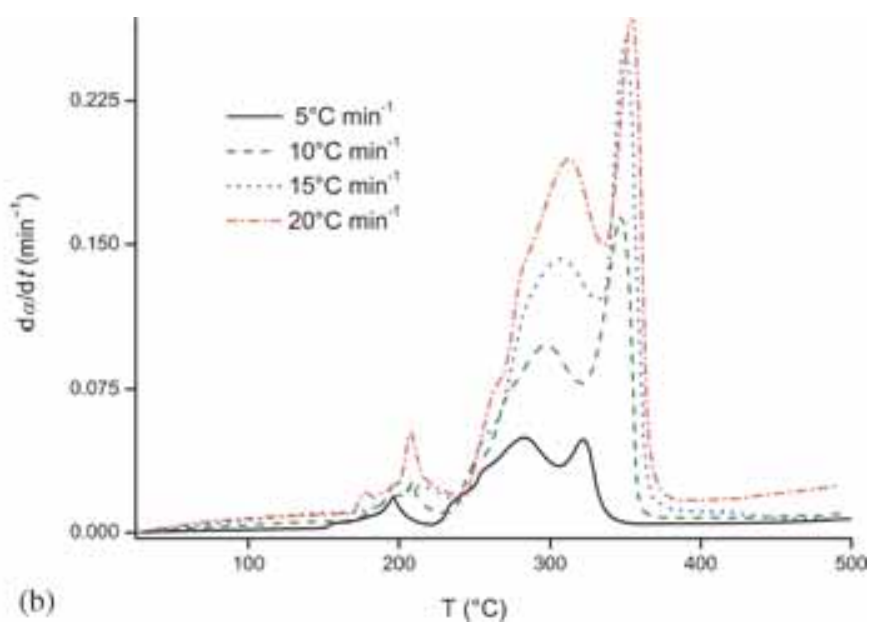

Figure 4. (a) Mass loss curves of UFC along with DTA at different heating rates and (b) reaction rate of UFC at different heating rates. 
final decomposition temperature (FDT) and the temperature corresponding to maximum rate of mass loss $\left(T_{\max }\right)[52,53]$. Besides this, Doyle suggested an efficacious parameter to estimate the inherent thermal stability of polymeric materials, called integral procedure decomposition temperature (IPDT) [54]. IPDT correlates the volatile parts of polymers and it might be helpful in obtaining the useful information about the structures of polymers and polymer composites. IPDT is defined by the following relations [55]:

$$
\operatorname{IPDT}\left({ }^{\circ} \mathrm{C}\right)=T_{i}+A^{*} K^{*}\left(T_{f}-T_{i}\right),
$$

whereas

$$
\begin{aligned}
A^{*} & =\frac{S_{b}+S_{c}}{S_{a}+S_{b}+S_{c}} \\
K^{*} & =1+\frac{S_{c}}{S_{b}} .
\end{aligned}
$$

In equation (16), $T_{i}$ is the IDT of polymer (usually corresponds to $5 \%$ mass loss), $T_{f}$ the FDT and $A^{*}$ and $K^{*}$ are constants that can be calculated by equations (17) and (18). In equations (17) and (18), $S_{a}$ and $S_{b}$ are the areas above and below the TG thermogram, respectively, while $S_{c}$ is the complementary area of oblong rectangle, as represented in figure 5a. By employing equations (16-18), following the procedure discussed above, the IPDT values of UFC at each heating rate has been calculated and shown in figure 5b. The IPDT data show that the intrinsic thermal stability of UFC is independent of heating rate with an average IPDT value of $445^{\circ} \mathrm{C}$. Under the similar experimental conditions, the IPDT value of UFC is found comparable to epoxy $\left(464^{\circ} \mathrm{C}\right)$ [56], which is a highly crosslinked 3D network forming thermosetting resin. The IPDT results show that the UFC resin is significantly stable.

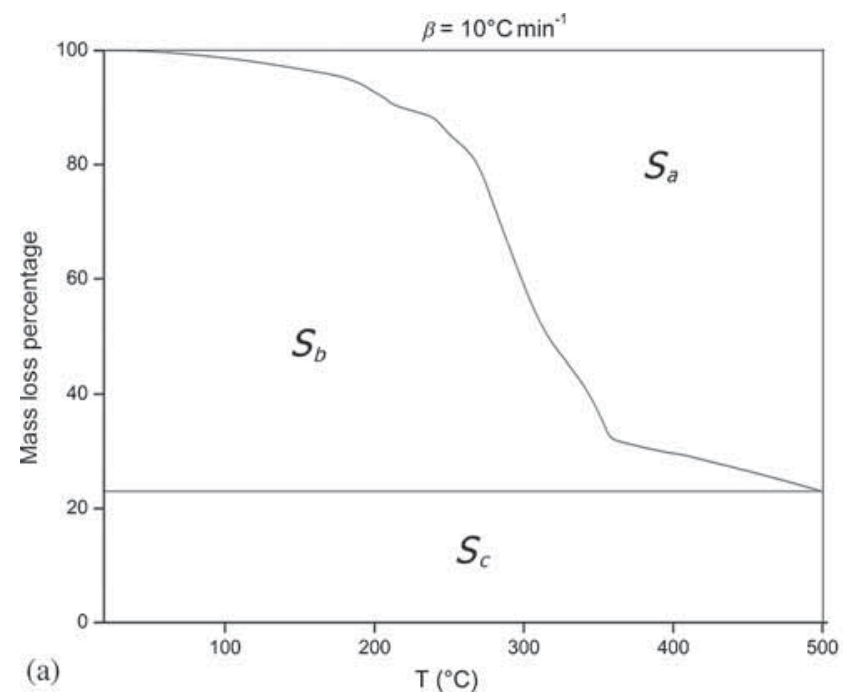

\subsection{Thermal degradation kinetics of UFC}

The complicated thermal behaviour of UFC could be fairly explained on the basis of isoconversional kinetics. Isoconversional kinetics may guide to the useful clues about the degradation pathway of UFC in terms of variation in its activation energy with the advancement of reaction. It is familiar that each and every isoconversional method has a certain error associated with it arising from numerical differentiation/integration of thermoanalytical data. Therefore, a set of linear/non-linear differential/integral isoconversional methods is used to verify and compare the variance of $E$ with $\alpha$, also called $E$ - $\alpha$ dependency. The differential method of Friedman, non-linear differential method, linear integral methods of OFW, KAS and Starink by generalized linear integral isoconversional method, and advanced isoconversional method of Vyazovkin have been utilized within the $\alpha$-domain $[0.05,1]$ with $\Delta \alpha=0.05$.

Figure $6 \mathrm{a}$ and $\mathrm{b}$ shows the results obtained by applying the Friedman's differential method and non-linear differential method, respectively; while figure $6 \mathrm{c}$ and d shows the application of generalized linear integral isoconversional method to calculate the $E-\alpha$ dependency by OFW, KAS and Starink's methods. At extreme values of $\alpha$, the straight lines in figure $5 \mathrm{~b}$ and $\mathrm{c}$ intensively deviate from the linearity. The activation energies at those regimes are not reliable and therefore neglected [53]. The reliable energies are obtained in the interval $[0.1,0.85]$ in all isoconversional methods. Figure $7 \mathrm{a}$ shows the results obtained by non-linear differential method. The comparison between the $E_{\alpha}$ values obtained by different isoconversional methods $v s . \alpha$ for UFC including error bars is represented in figure $7 \mathrm{~b}$. Figure $7 \mathrm{~b}$ shows that the activation energy values of UFC obtained by KAS, OFW and Starink methods are almost the same. A similar fact has been pointed out in a recent thermal degradation kinetic study of tin-filled epoxy composites [55]. Nevertheless, the variation in $E_{\alpha}$

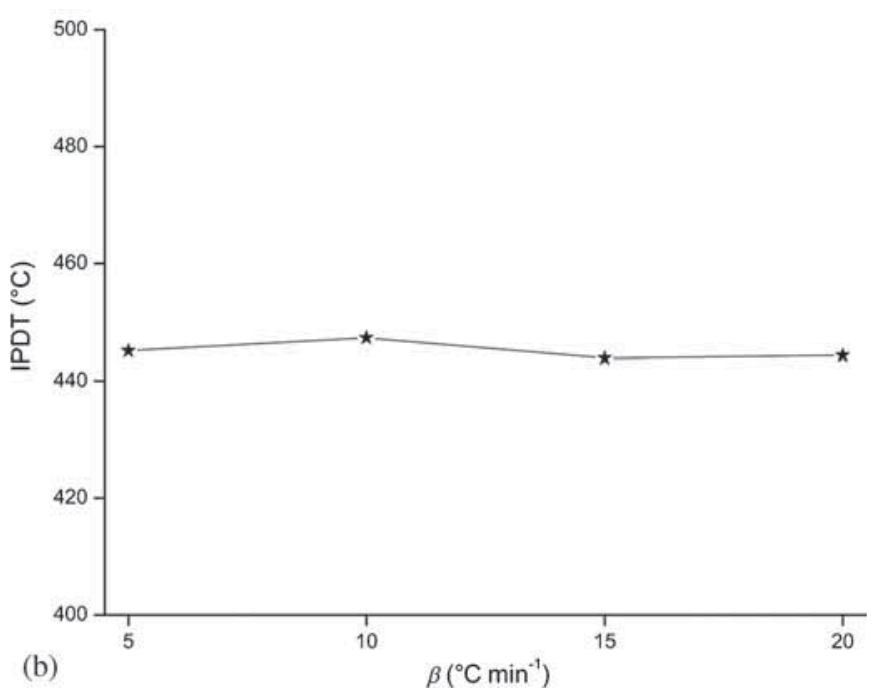

Figure 5. (a) A representation of the method to evaluate the inherent thermal stability of UFC at $\beta=10^{\circ} \mathrm{C} \mathrm{min}^{-1}$ and (b) plot of IPDT of UFC $v s$. heating rate. 

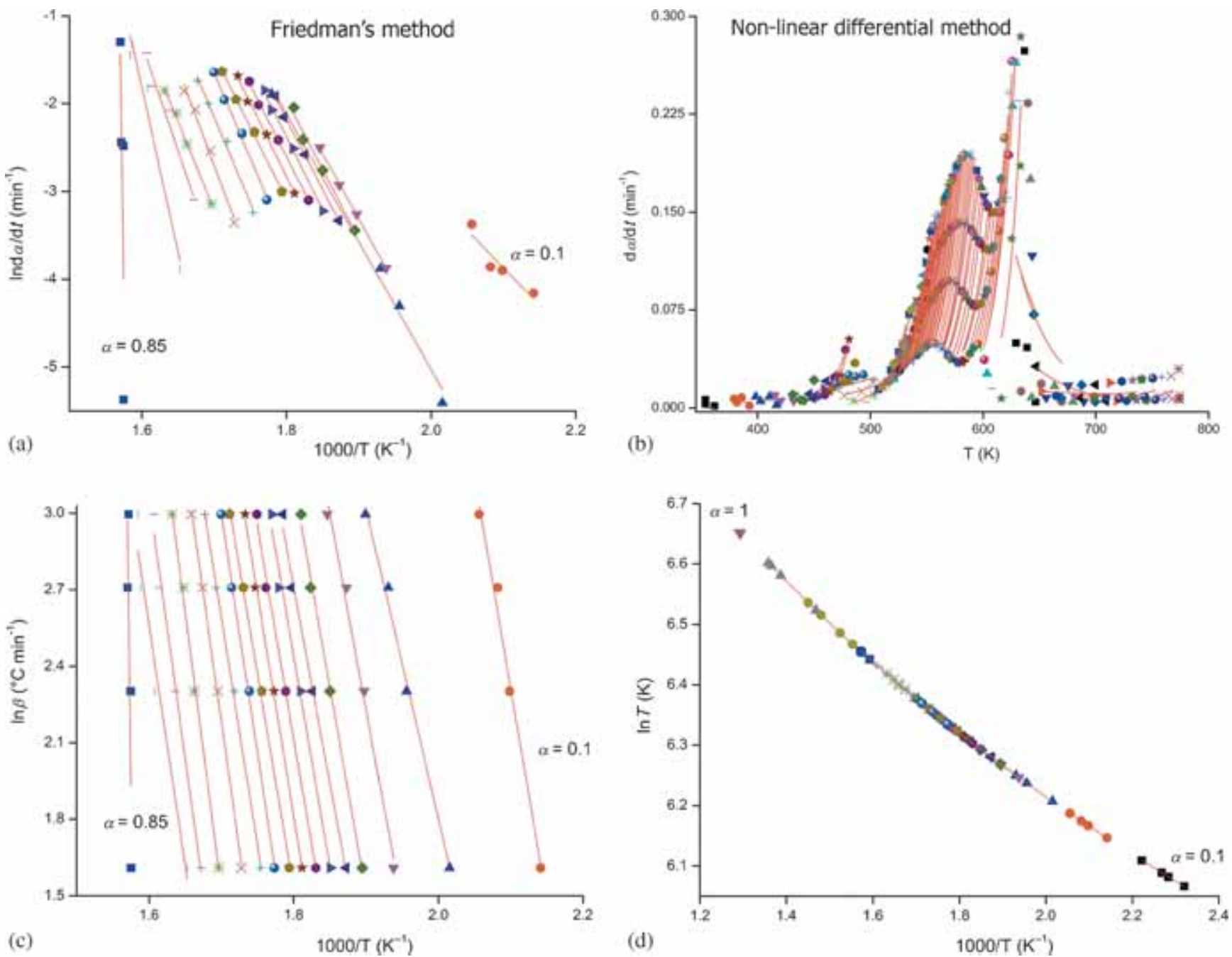

Figure 6. Evaluation of $E-\alpha$ dependency of UFC by (a) Friedman's method, (b) non-linear differential method and (c, d) generalized linear integral isoconversional method.
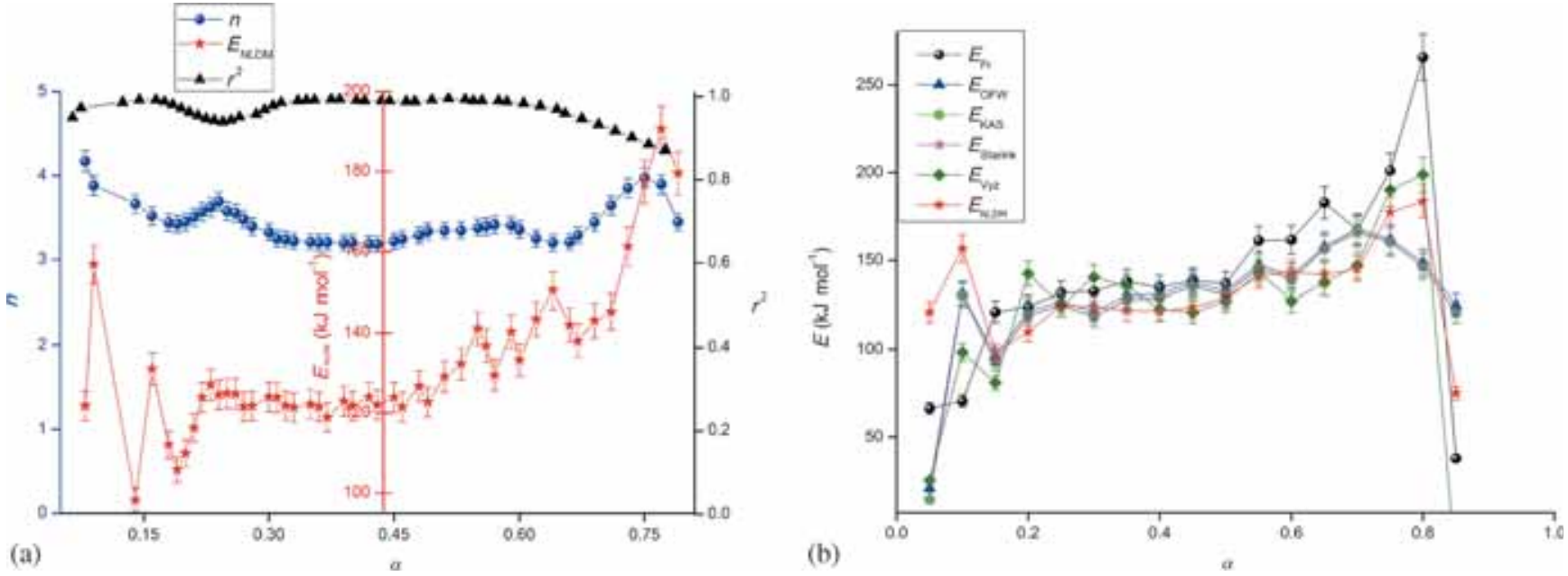

Figure 7. (a) Variation of the degradation activation energy of UFC, parameter $n$ and regression factor $r^{2}$ with the degree of conversion determined by non-linear differential method and (b) $E$ - $\alpha$ dependencies of UFC derived by different isoconversional methods. 
Table 2. Effective activation energies of the individual reactions in multi-step thermal degradation of UFC determined by isoconversional methods.

\begin{tabular}{lcccc}
\hline Isoconversional method & $\begin{array}{c}E_{1} \\
\left(\mathrm{~kJ} \mathrm{~mol}^{-1}\right)\end{array}$ & $\begin{array}{c}E_{2} \\
\left(\mathrm{~kJ} \mathrm{~mol}^{-1}\right)\end{array}$ & $\begin{array}{c}E_{3} \\
\left(\mathrm{~kJ} \mathrm{~mol}^{-1}\right)\end{array}$ & $\begin{array}{c}E_{4} \\
\left(\mathrm{~kJ} \mathrm{~mol}^{-1}\right)\end{array}$ \\
\hline Friedman & $86 \pm 10$ & $129 \pm 4$ & $153 \pm 8$ & $168 \pm 17$ \\
Non-linear differential method & $107 \pm 15$ & $120 \pm 3$ & $135 \pm 3$ & $145 \pm 17$ \\
Ozawa-Flynn-Wall & $83 \pm 15$ & $124 \pm 4$ & $143 \pm 5$ & $145 \pm 10$ \\
Kissinger-Akahira-Sunose & $79 \pm 15$ & $121 \pm 3$ & $141 \pm 5$ & $143 \pm 11$ \\
Starink & $79 \pm 15$ & $121 \pm 3$ & $141 \pm 4$ & $143 \pm 11$ \\
Vyazovkin & $68 \pm 11$ & $136 \pm 7$ & $133 \pm 10$ & $121 \pm 20$ \\
Average & 83 & 125 & 141 & 144 \\
\hline
\end{tabular}

with $\alpha$ has been found analogous in all the cases and the differences in the activation energies are more likely caused by the numerical integration/differentiation of thermoanalytical data while employing isoconversional methods.

4.5a Interpretation of $E$ - $\alpha$ dependency of UFC and mechanistic predictions: The reactions shown by UFC are one of the examples of complex solid-state reactions. Four different regions are marked in figure $7 \mathrm{~b}$, which represents the $E-\alpha$ dependency patterns of UFC obtained by different isoconversional methods. The effective activation energies in these regions have been shown in table 2 .

It is worth remarking that the activation energy values obtained by non-linear differential method are in comparison with the rest of isoconversional methods, especially at higher degree of conversion values. This is because the $E_{\alpha} / \mathrm{RT}$ factor attains a value in the range of 30 [20]. However, the higher average value of parameter $n$, i.e., 3.45 , as illustrated from figure $7 \mathrm{a}$, indicates predominantly the reaction complexity.

In $E-\alpha$ dependency of UFC, the first region ranges from 50 to $230^{\circ} \mathrm{C}$ corresponding to $(0,0.15]$ of $\alpha$, which provides information about the initial mass loss that could predominantly be due to the dehydration of resin and/or some weaker interactions present in the macromolecular structure of resin. The effective $E_{\alpha}$ value in this region is $83 \mathrm{~kJ} \mathrm{~mol}^{-1}$, which seems reasonable as the dehydration energy remains generally between 60 and $100 \mathrm{~kJ} \mathrm{~mol}^{-1}$. The second region ranges from 230 to $270^{\circ} \mathrm{C}$, which is related to $(0.15,0.35]$ of $\alpha$. The activation energy values are fairly stable in this region with an average value of $125 \mathrm{~kJ} \mathrm{~mol}^{-1}$ that might be assigned to the conversion of methyl ether functional groups into methylene functional groups. The third region starts from $270^{\circ} \mathrm{C}$ and ends at $350^{\circ} \mathrm{C}$ and corresponds to $(0.35,0.75)$ of $\alpha$. This region comprises competitive principle degradation reactions of urea-formaldehyde and cellulose and the structure formed by blending them together. The effective energy of reactions found in this region is $141 \mathrm{~kJ} \mathrm{~mol}^{-1}$. The fourth and the last region ranges from $350^{\circ} \mathrm{C}$ onward and is related to $[0.75,1]$ of $\alpha$. The $E_{\alpha}$ values show significant scattering in this region, probably due to the involvement of several reactions. As shown earlier, the values of $E_{\alpha}$ are unstable ahead $\alpha=0.85$; therefore, an average value of activation energy $144 \mathrm{~kJ} \mathrm{~mol}^{-1}$ in $[0.75,0.85]$ has been taken. In general, the activation energy of fourth step is mainly associated with the char formation. It is worth noting here that the common temperature ranges relevant to the degree of conversion intervals have been chosen by taking into account all the employed heating rates. This consideration is tacitly mentioned in section 4.4 while interpreting the probable physical significances of TGA/DTG and reaction rate curves of UFC (figure 4).

A somewhat analogous behaviour of the variation in activation energy with the reaction advancement has already been pointed out in epoxy and epoxy composites $[52,53,55]$. Although the fundamental difference between the $E-\alpha$ dependency patterns of epoxy resin and UFC resin is that the thermal degradation of epoxy consists of relatively limited number of reactions, therefore its thermal degradation can be kinetically simulated by logistic function-based autocatalytic reaction models (probably following nucleation/growth pathways) [55]. On the other hand, in UFC resin the individual reaction complexities of urea-formaldehyde and cellulose along with the additional reactions originating as a result of the interactions between urea-formaldehyde and cellulose generate a substantially intricate reaction profile with various consecutive/parallel reactions. The applicability of wellknown reaction model determination approaches thus become doubtful in the case of UFC thermal degradation [15], making isoconversional kinetics inevitable and appropriate.

\section{Conclusions}

On the basis of results and discussion, following concluding points are made:

- The structural characterization of UFC by SEM suggests its fair homogeneity with semi-crystalline structure. Further morphological analysis by FTIR and XRD predicts that the interactions between urea-formaldehyde and cellulose might result in new crystalline phases that are quite different from their individual components. CI of UFC reveals that approximately one-fourth of the resin constitutes of crystalline phases. Inherent thermal stability calculations show that UFC is considerably stable.

- TGA along with DTA suggest highly complicated reaction profile for UFC resin. It comprises a number of parallel and consecutive reactions occurring at long range of 
temperature. The individual thermal behaviours of UFC constituents are helpful in explaining its complicated thermal behaviour.

- Isoconversional kinetic analysis of UFC fairly elaborates its reaction complexity. The multi-step reaction profile of UFC is dealt on the basis of variation in activation energy with the reaction advancement arising from mechanism alteration during the reaction. The probable physical significance of the obtained kinetic parameters has also been explained.

\section{Acknowledgement}

We acknowledge the financial support from the Ministry of Economy and Competitiveness (MICINN), Spain, through the National Program for Fostering Excellence in Scientific and Technical Research (Project MAT2013-47972-C2-1-P).

\section{References}

[1] Meyer B 1979 Urea-formaldehyde resins (Reading, MA: Addison-Wesley)

[2] Lokensgard E 2008 Industrial plastics: theory and applications (New York: Delmar) 5th edn p 491

[3] Levendis D, Pizzi A and Ferg A 1992 Holzforschung 46263

[4] Hubbe M A, Rojas O J, Lucia L A and Sain M 2008 BioResources 3929

[5] Singha A S and Thakur V K 2010 Polym. Compos. 31459

[6] Zhang H, Zhang J, Song S, Wu G and Pu J 2011 BioResources 64430

[7] Basta A H, Saied H E, Winandy J E and Sabo R 2011 J. Polym. Environ. 19405

[8] Pinto G and Maaroufi A K 2005 J. Appl. Polym. Sci. 962011

[9] Pinto G and Maaroufi A K 2005 Polym. Compos. 26401

[10] Pinto G, Maaroufi A K, Benavente R and Pereña J M 2011 Polym. Compos. 32193

[11] Pinto G and Maaroufi A K 2012 Polym. Compos. 332188

[12] Vyazovkin S 2015 Isoconversional kinetics of thermally stimulated processes (Heidelberg: Springer)

[13] Vyazovkin S 2000 Int. Rev. Phys. Chem. 1945

[14] Vyazovkin S 2000 New J. Chem. 24913

[15] Vyazovkin S, Burnham A K, Craido J M, Pérez-Maqueda L A, Popescu C and Sbirrazzuoli N 2011 Thermochim. Acta 5201

[16] Wu W, Cai J and Liu R 2013 Ind. Eng. Chem. Res. 5214376

[17] Baroni E G, Tannous K, Rueda-Ordoez Y J and TinocoNavarro L K 2016 J. Therm. Anal. Calorim. 123909

[18] Brachi P, Miccio F, Miccio M and Ruoppolo G 2015 Fuel Proc. Tech. 130147

[19] Ren S and Zhang J 2013 Thermochim. Acta 56136

[20] Venkatesh M, Ravi P and Tewari S P 2013 J. Phys. Chem. A 11710162

[21] Sharma J K, Srivastava P, Singh G, Akhtar M S and Ameen S 2015 Mater. Sci. Eng. B 193181

[22] Brown M E and Gallagher P K 2008 Handbook of thermal analysis and calorimetry; recent advances, techniques and applications (Amsterdam: Elsevier) 5th edn p 503
[23] Friedman H L 1964 J. Polym. Sci. 6(C) 183

[24] Arshad M A and Maaroufi A K 2014 Thermochim. Acta 58525

[25] Burnham A K and Braun R L 1999 Energ. Fuel 131

[26] Criado J M, Pérez-Maqueda L A and Sánchez-Jiménez P E 2005 J. Therm. Anal. Calorim. 82671

[27] Dresser M J, Madey T E and Yates T J 1974 Surf. Sci. 42533

[28] Ibach H, Erley W and Wagner H 1980 Surf. Sci. 9229

[29] Soler J M and Garcia N 1983 Surf. Sci. 124563

[30] German R M 1996 Sintering theory and practice (New York: John Wiley)

[31] Fan J and Zeng J 2013 J. Appl. Math. Comput. 2199438

[32] Flynn J H 1997 Thermochim. Acta 30083

[33] Flynn J H and Wall L A 1966 J. Res. Nat. Bur. Standards-A: Phys. Chem. 70(A) 487

[34] Akahira T and Sunose T 1971 Sci. Technol. 1622

[35] Starink M J 2003 Thermochim. Acta 404163

[36] Vyazovkin S 2001 J. Comput. Chem. 22178

[37] Jada S S 1988 J. Appl. Polym. Sci. 351573

[38] Yang H, Yan R, Chen H, Lee D H and Zheng C 2007 Fuel 861781

[39] Xu F, Sun J X, Sun R, Fowler P and Baird M S 2006 Ind. Crop. Prod. 23180

[40] Smith B C 1998 Infrared spectral interpretation: a systematic approach (Boca Raton: CRC Press)

[41] Edoga M O 2006 Leonardo Elect. J. Pract. Tehnol. 963

[42] Samarzija-Jovanovic S, Jovanovic V, Konstantinovic S, Markovic G and Marinovic-Cincovic M 2011 J. Therm. Anal. Calorim. 1041159

[43] Park S, Baker J O, Himmel M E, Parilla P E and Johnson D K 2010 Biotechnol. Biofuels 31

[44] Roumeli E, Papadopoulou E, Pavlidou E, Vourlias G, Bikiaris D, Paraskevopoulos K M and Chrissafis K 2012 Thermochim. Acta $\mathbf{5 2 7} 33$

[45] Arafa I M, Fares M M and Braham A S 2004 Eur. Polym. J. 401477

[46] Siimer K, Kaljuvee T, Christjanson P and Lasn I 2006 J. Therm. Anal. Calorim. 8471

[47] Camino C, Operti C and Trossarelli L 1983 Polym. Degrad. Stab. 5161

[48] Zorba T, Papadopoulou E, Hatjiissaak A, Paraskevopoulos K M and Chrissafis K 2008 J. Therm. Anal. Calorim. 9229

[49] Spoljaric S, Wong K K, Pannirselvam M, Griffin G J, Shanks R A and Setunge S 2013 Chemeca 41805

[50] Malmeev V, Bourbigot S and Yvon J 2007 J. Anal. Appl. Pyrol. 80151

[51] Malmeev V, Bourbigot S, Bras M L and Yvon J 2006 J. Chem. Eng. Sci. 611276

[52] Arshad M A, Maaroufi A, Benavente R and Pinto G 2014 J. Mater. Environ. Sci. 51342

[53] Arshad M A, Maaroufi A, Benavente R, Pereña J M and Pinto G 2013 Polym. Compos. 342049

[54] Doyle C D 1961 Anal. Chem. 3377

[55] Arshad M A, Maaroufi A, Benavente R and Pinto G 2015 Polym. Compos. 369

[56] Chiang C L, Chang R C and Chiu Y C 2007 Thermochim. Acta 45397 